\title{
Eggs of a Female Japanese Quail Are More Likely to Be Fertilized by a Male That She Prefers
}

\author{
Kamini N. Persaud and Bennett G. Galef, Jr. \\ McMaster University
}

\begin{abstract}
Male Japanese quail (Coturnix japonica) that conspecific females preferred in a 10-min, forced-choice test of affiliative preference were more likely than were males not preferred in such a test to fertilize females' eggs when subsequently mated with them, although preferred and nonpreferred males mated equally often with females. Further, the probability that a nonpreferred male would fertilize a female's eggs was significantly increased if she watched while he courted and mated with another female. The results indicate that in Japanese quail (a) affiliative preference reliably predicts females' choices of fathers for their offspring and (b) females may have some degree of control over whether the males with whom they mate actually fertilize their eggs.
\end{abstract}

Because females generally invest more in their offspring than males, females typically should be more selective than males when deciding whether to engage in reproductive activities with a potential partner (Cunningham \& Birkhead, 1998; Trivers, 1972). However, in some species, females' mate choices are subverted by males forcing copulations (Clutton-Brock \& Parker, 1995; Smuts \& Smuts, 1993). Such sexual coercion is a common mating tactic of male fowl (Pizzari, 2001), including Japanese quail (Coturnix japonica; Adkins-Regan, 1995; Persaud \& Galef, 2003), the subject species in the experiments described here.

A male Japanese quail attempting to mate chases and pecks at a female, seizes feathers at the back of her head in his beak and often drags her around by her head feathers before pinning her down and jumping onto her back to achieve cloacal contact. To a human observer, many of the copulations in which female Japanese quail engage appear coerced (Wetherbee, 1961).

In some species that, like Japanese quail, appear to experience sexual coercion, females have been shown to play a greater role in determining the paternity of their offspring than might be expected, given the apparent inability of females to resist the advances of undesired males (Cunningham \& Birkhead, 1998). For example, female feral fowl (Gallus gallus) influence which males "force" copulation by uttering calls that promote competition among males and result in female coercion by males that are successful in competition with other males (Pizzari, 2001).

Even after a male copulates with a female, she may still be able to influence whether a mating episode results in fertilization of her

Kamini N. Persaud and Bennett G. Galef, Jr., Department of Psychology, McMaster University.

Kamini N. Persaud is now in the Department of Biology, Queens University, Kingston, Ontario.

We thank Sarah Watkins for technical assistance. This work was funded by a Natural Sciences and Engineering Research Council of Canada grant to Bennett G. Galef, Jr. Kamini N. Persaud was supported by a Natural Sciences and Engineering Research Council predoctoral fellowship.

Correspondence concerning this article should be addressed to Bennett G. Galef, Jr., Department of Psychology, McMaster University, Hamilton, Ontario L8S 4K1 Canada. E-mail: galef@mcmaster.ca eggs through postcopulatory processes (Birkhead \& Møller, 1992; Cunningham \& Birkhead, 1998). For example, when forced to mate with subdominant males, female feral fowl (Gallus gallus domesticus) will expel ejaculates immediately after insemination (Pizzari \& Birkhead, 2000). Like female fowl, a female Japanese quail can expel sperm from her cloaca immediately after a male has inseminated her (Adkins Regan, 1995) although, in quail, there is no evidence that ejection of sperm-containing foam after copulation affects the fertilization success of inseminating males (Adkins-Regan, 1995; authors' unpublished observation). Female quail also have sperm storage tubules that, it has been suggested, could be used to bias paternity if females can selectively store or utilize sperm from different males (Birkhead \& Møller, 1992; Eberhard, 1996). Both female quails' ability to void sperm and their potential ability to selectively retain and utilize sperm suggest that females' mate preferences might affect the reproductive success of their mates.

In two experiments, we determined whether (a) a female's association with a male in a test of affiliative preference predicted the probability that he would fertilize her eggs (Experiment 1) and (b) observation by a female of a male mating with another female, a manipulation known to increase a female quail's affiliation with nonpreferred males, would increase the frequency with which females who mated with such males produced fertilized ova (Experiment 2).

\section{Experiment 1: Female Mate Choice and Probability of Fertilization}

If a female Japanese quail exerts some control over whether a male will fertilize her eggs, then, all else being equal, a female should be more likely to lay fertilized eggs if mated with a male that she had preferred than if mated with a male she had not preferred in a prior test of affiliative preference.

\section{Method}

\section{Subjects}

Twenty-seven female and 27 male 52-day-old Japanese quail obtained from a local commercial breeder (Speck's Poultry Farm, Vineland, On- 
tario, Canada) served as subjects. After we transported the birds to our laboratory (Hamilton, Ontario, Canada), we placed them in individual, commercial quail cages $(55 \times 55 \times 110 \mathrm{~cm}$ : Berry Hill Farms, St. Thomas, Ontario, Canada) maintained in a temperature- and humidity-controlled colony room illuminated for $16 \mathrm{hr} /$ day.

All subjects had ad libitum access to Mazuri Pheasant Starter 5637 (PMI Feeds, St. Louis, Missouri) and water. For environmental enrichment, twice each week we provided each bird with a handful of autoclaved hay.

To allow birds to come into breeding condition, we waited 30 days after bringing them to the laboratory before starting the experiment. When females started to lay an egg a day, at approximately 70 days of age, we considered them in breeding condition.

Male Japanese quail begin to engage in complete copulations when approximately 35 days old, an age when spermatozoa are known to be present in large numbers in both their testes and vas deferens (Mills, Crawford, Domjan, \& Faure, 1997). To ensure that our 70-day-old male subjects would be sexually active during the experiment, we habituated them to courting and mating in the experimental setting. We paired each male in the central compartment of the experimental apparatus (see Apparatus; Figure 1), for $5 \mathrm{~min} /$ day, with a series of sexually mature female quail from our colony until he had copulated successfully on 2 days in succession. Males first participated in the experiment 1 week after the second of these matings.

To begin the experiment, we randomly assigned each female to two males with whom she had not been paired during habituation and then randomly assigned these trios to conditions. During the experiment, each focal female served as a subject only once, and each male participated twice in the experiment, once as a member of each of two trios. No males served together in more than one trio, and males never participated in the experiment more than once on any day.

\section{Apparatus}

We conducted experiments in the enclosure illustrated in Figure 1. The enclosure $(122 \times 61 \times 30.5 \mathrm{~cm})$, constructed of painted plywood and transparent Plexiglas, rested on an aluminum tray covered with disposable absorbent paper pads (Tray Liners, Lilo Products, Hamilton, Ontario, Canada). Partitions of 0.5 -in. $(1.57 \mathrm{~cm})$ hardware cloth located $30.5 \mathrm{~cm}$ from each end of the enclosure divided it into two "end compartments" and a "central compartment." To facilitate determination of which end compartment of the apparatus a female was nearer, we drew a line from top to

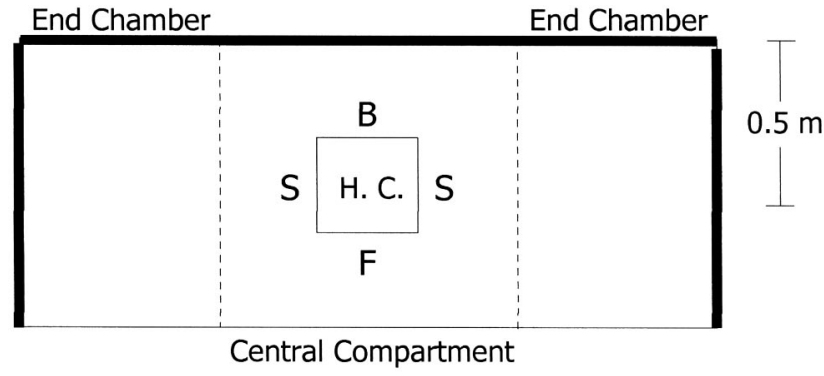

\section{T.V.}

Figure 1. Overhead view of the apparatus used in Experiments 1 and 2. Heavy lines indicate opaque walls, light lines indicate transparent Plexiglas walls, and dashed lines indicate hardware-cloth partitions. T.V. = closedcircuit TV; H.C. = holding cage; $\mathrm{F}$ and $\mathrm{B}=$ front and back walls, respectively; and $\mathrm{S}=$ side walls of the holding cage that were covered with Bristol board during the observation phase of Experiment 2. bottom of the Plexiglas front wall of the central compartment at its midpoint. An opening $(25.4 \times 25.4 \mathrm{~cm})$ in the center of the Plexiglas roof of the central compartment permitted us to raise or lower a transparent Plexiglas holding cage $(25.2 \times 25.2 \times 40.6 \mathrm{~cm})$ using a rope and pulley system.

A color CCTV video camera (Panasonic WV-CP412) attached to a video recorder (Panasonic AG-1240) and color monitor (CT 1331Y) faced the Plexiglas front wall of the enclosure and allowed observation and recording of all behavior in the apparatus.

\section{Procedure}

To ensure that there were no sperm remaining in females' sperm storage tubules from copulations during habituation, we first isolated each female from physical contact with males for 14 days (Adkins-Regan, 1995). The experiment proper consisted of two 10-min phases. The initial "choice" phase began with a male placed in each end compartment of the apparatus and a female restrained in the holding cage. We waited 1 min for subjects to settle down, then raised the holding cage to release the female. After the female took her first step, we determined the time that she spent on each side of the midline of the central compartment. We considered the female to have preferred whichever male she was closer to for more than half of the choice phase.

In the subsequent "copulation" phase, we placed each female in the end chamber containing either her preferred $(n=13)$ or her nonpreferred $(n=$ 14) male and allowed the pair to mate for $10 \mathrm{~min}$. We monitored both choice and copulation phases on closed-circuit TV and recorded the copulation phase for later scoring.

\section{Examination of Eggs}

For 12 days following mating of each focal female, we collected all of the eggs that she laid, labeled them with indelible ink, and placed them for 5 days in a humidity-controlled incubator that maintained the eggs at $99^{\circ} \mathrm{F}$ and rotated them once every $2 \mathrm{hr}$ (Hova-Bator Incubator, Model 2362N, GQF Manufacturing; Savannah, Georgia). After 5 days of incubation, an experimenter who was blind to the group assignment of females whose eggs she examined opened each egg and determined whether it contained a blood spot indicating fertilization (Adkins-Regan, 1995). Although this measure of egg fertilization did not detect any embryos that might have died during the first 5 days of incubation, it proved sufficiently sensitive to determine whether females' preferences affected males' success in fertilizing their eggs.

\section{Behavioral Analyses}

An experimenter, again blind to the group assignment of females, scored the video recording of each 10-min copulation phase for attempted and successful copulations. We identified successful copulations by the distinct pause that occurs while sperm transfer takes place following mounting of a female by a male and the lowering of his cloaca into contact with hers (Mills et al., 1997). An attempted copulation was identical to a successful copulation except that no pause in male activity during which sperm transfer may have occurred could be discerned.

\section{Results and Discussion}

\section{Fertilization}

Focal females paired with their respective preferred males were more likely to lay fertilized eggs than were focal females paired with their respective nonpreferred males (Fisher's exact test, $p=$ .02; Figure 2). Because each female laid either no fertilized eggs or several fertilized eggs, females paired with their preferred males 


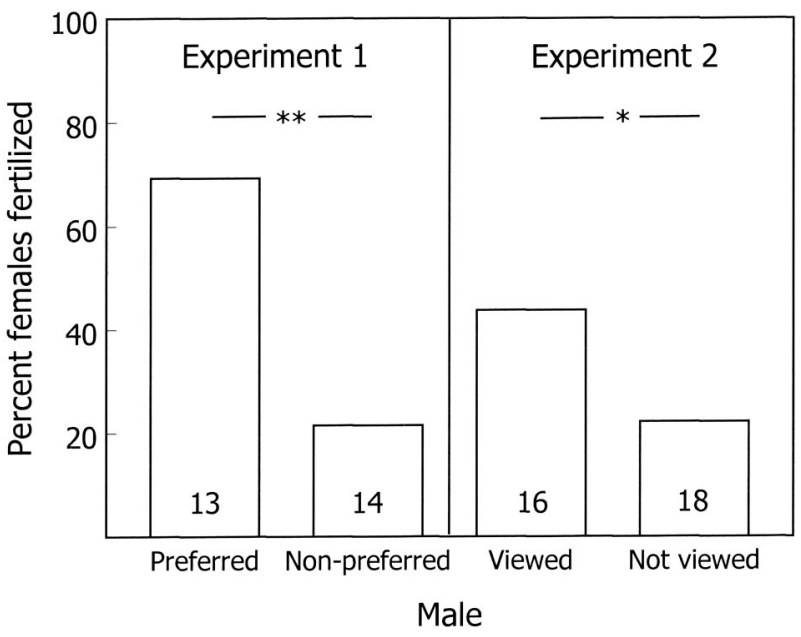

Figure 2. Percentage of focal females laying fertilized eggs in Experiments 1 and 2 after (Experiment 1) pairing with either a preferred or a nonpreferred male and (Experiment 2) pairing with a nonpreferred male either viewed or not viewed mating with another female. Numbers inside histograms $=N$ /group. $* p<.05 . * * p<.02$.

also laid a greater number (Mann-Whitney $U$ test; $U=51.5, N_{I}=$ $\left.13, N_{2}=14, p<.05\right)$ and greater percentage of fertilized eggs (Mann-Whitney $U$ test; $U=54.0, N_{1}=13, N_{2}=14, p<.05$ ) than did females mated with their nonpreferred males.

\section{Behavior}

We omitted three females from behavioral analyses because of failure of the video recorder during the copulation phase. Females mated with their preferred males engaged in as many attempted copulations (Mann-Whitney $U$ test; $U=69.5, N_{1}=10, N_{2}=14$, $n s$; Figure 3), successful copulations (Mann-Whitney $U$ test; $U=$ 57.5, $N_{1}=10, N_{2}=14, n s$; Figure 3 ), or both attempted and successful copulations considered together (Mann-Whitney $U$ test; $\left.U=62.5, N_{1}=10, N_{2}=14, n s\right)$ as did females mated with their nonpreferred males.

The results of Experiment 1 show that a male's success in fertilizing a female's eggs was affected by her preference for him. Although females engaged in no more successful copulations with preferred than with nonpreferred males, preferred males still fertilized the eggs of their mates more frequently than did nonpreferred males.

\section{Experiment 2: Mate-Choice Copying and Probability of Fertilization}

The results of Experiment 1 are consistent with the hypothesis that a female's preference for a male influences his probability of success in fertilizing her eggs. However, the results of Experiment 1 are also consistent with the hypothesis that female quail can identify males that are more likely to inseminate them and prefer to affiliate with such males. We undertook Experiment 2 to examine the latter possibility by experimentally enhancing females' preferences for males that they did not prefer and determining whether such enhancement of preference also increased the likelihood that a nonpreferred male would fertilize his partner's eggs.
If increasing a female's affiliative preference for a male also increased his probability of fertilizing her eggs, it would be difficult to argue that the reproductive advantage of preferred males was a consequence of females preferring to affiliate with males that were more likely to fertilize them.

In a series of experiments, White and Galef (Galef \& White, 1998; White \& Galef, 1999a, 1999b, 2000) found that the tendency of a female Japanese quail to affiliate with a nonpreferred male increases after she observed him court and mate with another female. Such mate-choice copying has been hypothesized to both decrease the cost to females of appraising males and to increase the probability that females with a less than average ability to detect desirable mates will choose superior partners (Gibson \& Höglund 1992).

If a female's affiliative preference for a male influences the probability that he fertilizes her eggs, then a female that observes a male she did not prefer in a test of affiliative preference court and mate with another female before being mated with him should show an increased probability of laying fertilized eggs. To the contrary, if female quail detect and prefer males that are more likely to fertilize their eggs, then allowing a female to watch a nonpreferred male court and mate should not affect the probability that he will fertilize her eggs when mated with her.

In the present experiment, we first allowed a "focal" female to choose between a pair of males, then either allowed or did not allow her to watch while her nonpreferred male mated with another female. We then paired all focal females with their respective nonpreferred males and determined whether each focal female produced fertilized eggs

\section{Method}

\section{Subjects}

Forty-one female and 35 male Japanese quail, obtained, housed, and maintained as described in methods of Experiment 1 but that had not participated in Experiment 1, served as subjects. Six of these females served only as "model" females (see Procedure), and we randomly as-

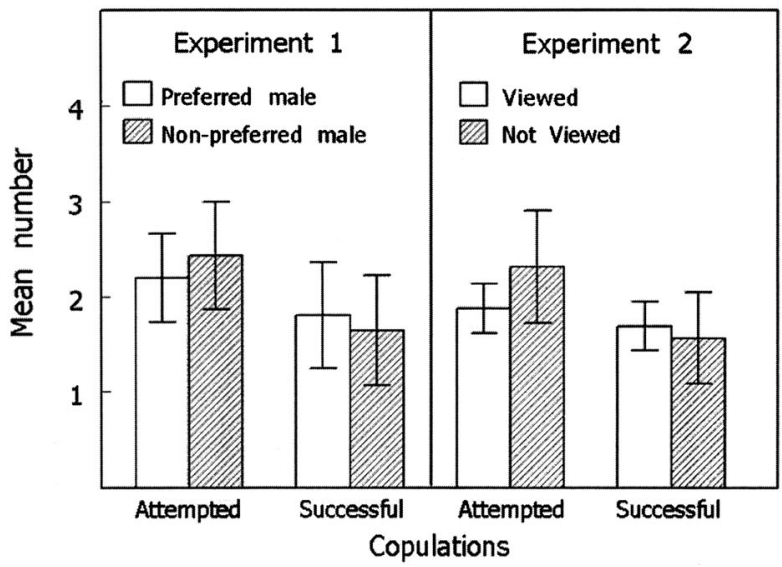

Figure 3. Mean number of attempted and successful copulations experienced by focal females paired with (Experiment 1) either preferred or nonpreferred males and (Experiment 2) males that were either viewed or not viewed mating with another female. Error bars represent 1 standard error of the mean. 
signed the remaining 35 "focal" females and 35 males to 35 trios, each consisting of two males and a focal female that had been 14 days without physical contact with males. As in Experiment 1, each focal female served as a subject only once, and each male participated twice in the experiment, once as a member of each of two trios. Again, as in Experiment 1, no males served together in more than one trio, and males never participated in the experiment more than once on any day.

\section{Apparatus}

We used the same apparatus that we used in Experiment 1, except that, during the observation phase (see Procedure), we attached to two of the sides of the holding cage pieces of black Bristol board, each the size of one wall of the holding cage $(50 \times 25 \mathrm{~cm}$; see Figure 1$)$. When we attached opaque barriers to the sidewalls of the holding cage, a focal female restrained within it could not see into the end compartments containing males. When we attached opaque barriers to the front and back walls of the holding cage, a focal female could see into the end compartments and observe the males that they contained.

\section{Procedure}

Each trial consisted of three phases. As in Experiment 1, we first conducted a 10-min choice test to determine each focal female's affiliative preference between a pair of males. During the subsequent observation phase, we returned the focal female to the holding cage and attached the opaque barriers either to the front and back (viewed condition) or side (not-viewed condition) walls of the holding cage. We then placed a model female in the end chamber of the enclosure that contained a focal female's nonpreferred male and left the model female and nonpreferred male to court and mate for $10 \mathrm{~min}$.

At the end of the 10-min observation period, we removed the model female and opaque barriers from the apparatus and left the focal female and males undisturbed for $20 \mathrm{~min}$ so that mated males could recover from their sexual contact with the model female. Last, we removed the focal female from the holding cage and placed her for $10 \mathrm{~min}$ in the end compartment containing her nonpreferred male. We recorded the behavior of each pair on videotape for subsequent analysis.

\section{Egg Incubation}

As in Experiment 1, we collected all of the eggs laid by focal females each day for 12 days and incubated them for 5 days. All but one female laid one egg per day.

\section{Results and Discussion}

Because of failure of the video recorder during the copulation phase, we could not analyze the behavior of two females. We also did not use any of the data collected from one focal female who did not lay any eggs after mating because we considered her to be ill.

Nine of the 16 focal females assigned to the viewed condition laid fertilized eggs, whereas only 4 of the 18 focal females assigned to the not-viewed condition did so, Fisher's exact test, $p<$ .10 ; chi-square test, $\chi^{2}(1, N=34)=4.15, p<.05$ (Figure 2). As in Experiment 1, because each focal female laid either no fertilized eggs or almost all fertilized eggs, focal females assigned to the viewed condition also laid a greater number (Mann-Whitney $U$ test; $\left.U=92.5, N_{1}=16, N_{2}=18, p<.05\right)$ and a greater percentage of fertilized eggs (Mann-Whitney $U$ test; $U=91.5$, $\left.N_{1}=16, N_{2}=18, p<.05\right)$ than did females assigned to the not-viewed condition.
Focal females assigned to viewed and not-viewed conditions were equally likely to participate in attempted copulations (MannWhitney $U$ test; $U=114.5, N_{1}=N_{2}=16, n s$; Figure 2), successful copulations (Mann-Whitney $U$ test; $U=120.5, N_{1}=$ $N_{2}=16, n s$; Figure 2), or both attempted and successful copulations considered together (Mann-Whitney $U$ test; $U=126.5$, $\left.N_{1}=N_{2}=16, n s\right)$.

The results of the present experiment indicate that the reproductive advantage of preferred males found in Experiment 1 did not result from females identifying and choosing more potent males. In addition, these results show that observing a previously nonpreferred male mate increases not only a female's affiliative preference for him but also the probability that he will fertilize her eggs.

\section{General Discussion}

Taken together, the results of Experiments 1 and 2 suggest that the mate preferences of female quail can affect their reproduction. Like house mice (Mus musculus), in which females paired with their preferred males produce more litters than females paired with their nonpreferred males (Drickamer, Gowaty, \& Holmes, 2000), female quail are more likely to produce offspring when paired with males they prefer to remain near.

How a female quail's preference for a male affected his success in fertilizing her eggs is far from clear. The results of Experiments 1 and 2, respectively, showed that (a) females paired with males that they did not prefer participated in as many copulations as females paired with males that they did prefer (Experiment 1) and (b) enhancing a female's preference for a male did not change the frequency with which she copulated with him. Females were not simply mating more frequently with males that they preferred. Further, the results of Experiment 2 excluded the possibility that female Japanese quail simply identified and preferred to affiliate with males that were more likely to fertilize their eggs.

That female choice influenced probability of fertilization and not frequency of copulation suggests that females may have exercised choice during or after copulation. Consistent with this view, in a study of the fertilization success of male quail that succeeded in transferring sperm to females during a single copulation, Adkins-Regan (1995) found that females that ran from a male's initial approach were less likely than females that did not run from a male's initial approach to lay fertilized eggs. It was, in AdkinsRegan's (1995) words, “as if running indicates behavioral rejection of the male and can be followed through with physiological rejection of his sperm" (p. 1413). A female's affiliative preference may similarly predict a "choice" that she exercises only after copulating.

Much recent attention has focused on the possibility that females can exert postcopulatory, or cryptic, mate choice defined by Birkhead and Pizzari (2002) as the "ability of a female to bias the fertilization success of the males that copulate and inseminate her" (p. 262). A variety of mechanisms for cryptic mate choice have been documented in insects and some bird species (for a review, see Eberhard, 1996). Although the present experiments provide no direct evidence of cryptic mate choice, the finding that preferred male quail were more likely to fertilize females despite not copulating more frequently than nonpreferred males suggests that female Japanese quail can exercise postcopulatory mate choice. As mentioned in the introduction, female Japanese quail can eject 
sperm from their cloaca, possess several discrete sperm storage tubules, and are frequently subjected to sexual coercion, all characteristics of females of species that are likely to engage in mate choice after copulation (Eberhard, 1996).

It is also possible that female quail influence fertilization of their eggs indirectly rather than directly. In the years since we initiated the present experiments, it has been shown that male fowl can modulate the sperm content of their ejaculate in response to a variety of cues (Pizzari, Cornwallis, Løvlie, Jakobsson, \& Birkhead, 2003; Pizzari, Froman, \& Birkhead, 2002; Wedell, Gage, \& Parker, 2002). Males' sperm stores are limited, and a female mating with a male she does not prefer may be more likely than a female mating with a preferred male to reject her partner's sperm after copulating. A male that had determined that a female did not prefer him might not invest as many sperm in his ejaculate when mating with her as when mating with a female that did prefer him. However, even if differences in males' investment of sperm when mating with females that did and did not prefer them caused the observed difference in fertilization rates of females in Experiment 1 , such differential male investment of sperm would still be an indirect result of female preference.

The results of Experiment 2, like those of Experiment 1, can be understood as reflecting males' modulation of their investment of sperm in female partners. We designed Experiment 2 so that a female assigned to the viewed condition could observe her nonpreferred male while he copulated with a model female. As a result, during the observation phase of Experiment 2, a nonpreferred male could also see the focal female while courting and mating with the model female. Thus, a male assigned to the viewed condition was in the presence of two females during the observation phase and might have reserved sperm for possible future matings with the focal female (Pizzari et al., 2003). Males assigned to the not-viewed condition were not able to see their focal females while mating with model females and might not have made a similar accommodation. However, it is not obvious why males that were not making a full commitment of sperm to focal females, and were therefore less likely to fertilize them, would not also invest less time and energy in courting and copulating with females than males that were not reserving sperm for potential future copulations.

Whether the mechanism responsible for the observed differences in the probability that preferred and nonpreferred males would fertilize females' eggs reflected male choice, female choice, or some combination of the two cannot be determined from the results of the present experiments. Indeed, given the difficulty of simultaneously monitoring the amount of sperm in a male's ejaculate and his success in fertilizing a female with whom he mates, determining the relative contribution of each member of a mated pair to a male's reproductive success will be difficult.

Why female Japanese quail prefer the males that they do is also not clear, and unpublished data from our laboratory indicate that females are not consistent in their preferences for males. Gowaty, Steinichen, and Anderson (2002) have shown, in fruit flies (Drosophila pseudoobscura), that permitting males and females to choose their mates increases their reproductive success. As we have found in female quail (unpublished data), Gowaty et al. (2002) found no consistency in the preference of either male or female Drosophila for particular members of the opposite sex. They interpreted such idiosyncratic preferences as reflecting choice of genetically compatible mates that would produce more and better quality offspring. The finding in Experiment 2 that socially acquired information can change the probability that a nonpreferred male will fertilize a female's eggs suggests that, in Japanese quail, idiosyncratic mate preferences of females are not a consequence of individual females seeking genetically compatible partners. If female quail were seeking genetically compatible partners, their choice of males should not be influenced by observing the mating behavior of other females.

The present results do show that, in the circumstances examined, (a) a female Japanese quail's preference for a male predicted whether copulation with that male would result in fertilization of her eggs, and (b) increasing a female's preference for a male through social learning increased the probability that he would subsequently fertilize her eggs. The results thus add to substantial literatures suggesting that (a) even in mating systems where sexual coercion occurs frequently, females' preferences can directly or indirectly affect males' fertilization success and (b) females observing the mate choices of others obtain information that affects their subsequent reproductive activity. How far those results can be generalized remains to be determined. Caution must always be exercised when extrapolating from artificial to natural environments (Galef, 1984; Wolff, 2003) or from domesticated to wild populations. It is surely possible that studies of 10-min mating bouts in domesticated quail restrained in small enclosures do not accurately reflect the sexual interactions of free-living quail. Unfortunately, little is known about the mating behavior of Japanese quail in the wild; thus, little can be said about the relationship between our observations and the behavior of free-living, wild individuals. However, in an investigation of effects of domestication on Japanese quail, Nichols (1991) reported that "domestic quail showed a behavioral repertoire much like feral quail" (p. iii), and we are presently studying sexual interactions between male and female Japanese quail in an environment providing the opportunity for females to escape and hide from males.

\section{References}

Adkins-Regan, E. (1995). Predictors of fertilization in the Japanese quail, Coturnix japonica. Animal Behaviour, 50, 1405-1415.

Birkhead, T. R., \& Møller, A. P. (1992). Sperm competition in birds: Evolutionary causes and consequences. San Diego, CA: Academic Press.

Birkhead, T. R., \& Pizzari, T. (2002). Postcopulatory sexual selection. Nature Reviews Genetics, 3, 262-272.

Clutton-Brock, T. H., \& Parker, G. A. (1995). Sexual coercion in animal societies. Animal Behaviour, 49, 1345-1365.

Cunningham, E. J. A., \& Birkhead, T. R. (1998). Sex roles and sexual selection. Animal Behaviour, 56, 1311-1321.

Drickamer, L. C., Gowaty, P. A., \& Holmes, C. M. (2000). Free female mate choice in house mice affects reproductive success and offspring viability and performance. Animal Behaviour, 59, 371-378.

Eberhard, W. G. (1996). Female control: Sexual selection by cryptic female choice. Princeton, NJ: Princeton University Press.

Galef, B. G., Jr. (1984). Reciprocal heuristics: A discussion of the relationship of the study of learned behavior in laboratory and field. Learning and Motivation, 15, 479-493.

Galef, B. G., Jr., \& White, D. J. (1998). Mate-choice copying in Japanese quail, Coturnix coturnix japonica. Animal Behaviour, 55, 542-552.

Gibson, R. M., \& Höglund, J. (1992). Copying and sexual selection. Trends in Ecology and Evolution, 7, 229-232. 
Gowaty, P. A., Steinichen, R., \& Anderson, W. W. (2002). Mutual interest between the sexes and reproductive success in Drosophila pseudoobscura. Evolution, 56, 2537-2540.

Mills, A. D., Crawford, L. L., Domjan, M., \& Faure, J. M. (1997). The behavior of the Japanese quail Coturnix japonica. Neuroscience and Biobehavioral Reviews, 21, 261-281.

Nichols, C. R. (1991). A comparison of the reproductive and behavioural differences in feral and domestic Japanese quail. Unpublished doctoral dissertation, University of British Columbia, Vancouver, British Columbia, Canada.

Persaud, K. N., \& Galef, B. G., Jr. (2003). Female Japanese quail aggregate to avoid sexual harassment by conspecific males: A possible cause of conspecific cueing. Animal Behaviour, 65, 89-94.

Pizzari, T. (2001). Indirect partner choice through manipulation of male behaviour by female fowl, Gallus gallus domesticus. Proceedings of the Royal Society of London: Series B, 268, 181-186.

Pizzari, T., \& Birkhead, T. R. (2000). Female feral fowl eject sperm of subdominant males. Nature, 405, 787-789.

Pizzari, T., Cornwallis, C. K., Løvlie, H., Jakobsson, S., \& Birkhead, T. R. (2003, November 6). Sophisticated sperm allocation in male fowl. $\mathrm{Na}$ ture, 426, 70-74.

Pizzari, T., Froman, D. P., \& Birkhead, T. R. (2002). Pre- and postinsemination episodes of sexual selection in the fowl, Gallus g. domesticus. Heredity, 88, 112-116.

Smuts, B. B., \& Smuts, R. W. (1993). Male aggression and sexual coercion of females in nonhuman primates and other mammals: Evidence and theoretical implications. Advances in the Study of Behavior, 22, 1-63.

Trivers, R. L. (1972). Parental investment and sexual selection. In D. Campbell (Ed.), Sexual selection and the descent of man (pp. 136-179). Chicago: Aldine-Atherton.

Wedell, N., Gage, M. J. G., \& Parker, G. A. (2002). Sperm competition, male prudence and sperm-limited females. Trends in Ecology and Evolution, 17, 313-320.

Wetherbee, D. K. (1961). Investigation into the life history of the common coturnix. American Midland Naturalist, 65, 168-186.

White, D. J., \& Galef, B. G., Jr. (1999a). Affiliative preferences are stable and predict mate choices in both sexes of Japanese quail, Coturnix japonica. Animal Behaviour, 58, 865-871.

White, D. J., \& Galef, B. G., Jr. (1999b). Mate choice copying and conspecific cueing in Japanese quail, Coturnix coturnix japonica. Animal Behaviour, 57, 465-473.

White, D. J., \& Galef, B. G., Jr. (2000). Differences between the sexes in direction and duration of response to seeing a potential sex partner mate with another. Animal Behaviour, 59, 1235-1240.

Wolff, J. O. (2003). Laboratory studies with rodents: Facts or artifacts? Bioscience, 53, 421-427.

Received April 7, 2004

Revision received September 15, 2004

Accepted September 19, 2004 